\title{
ANALISIS KOMPETENSI TENAGA KEPENDIDIKAN DI SEKOLAH MENENGAH ATAS NEGERI 18 GARUT
}

\author{
Ikeu Kania \\ Universitas Garut \\ Email: ikeukania@fisip.uniga.ac.id
}

\begin{abstract}
Abstrak
Kepala sekolah, administrator sekolah, dan personel lainnya memberikan pendidikan yang berkualitas. Pegawai administrasi sekolah adalah tenaga pendidik yang membantu administrasi sekolah. Penelitian ini bertujuan untuk mengevaluasi bagaimana tenaga kependidikan dapat meningkatkan kualitas pelayanan di SMA Negeri 18 Garut. Penelitian ini menggunakan penelitian kualitatif dengan analisis deskriptif. Berdasarkan penelitian, tenaga kependidikan SMA Negeri 18 Garut memiliki tiga keterampilan untuk meningkatkan kualitas pelayanan sesuai dengan Peraturan Pemerintah Pendidikan Nasional No. Upaya peningkatan administrasi sekolah di SMA Negeri 18 Garut meliputi pelatihan tenaga kependidikan, sidik jari di setiap masuk dan keluar sekolah, pertemuan motivasi dan moral bulanan, dan studi banding dengan sekolah lain. Memberikan asuhan kepada tenaga pengajar SMA Negeri 18 Garut.
\end{abstract}

Kata Kunci: Kompetensi, Tenaga kependidikan, Administrasi Sekolah.

\begin{abstract}
Principals, school administrators, and other personnel deliver quality education. School administration employees are educators that help school administration. This research seeks to evaluate how education staff may improve service quality at SMA Negeri 18 Garut. This study employed qualitative research with descriptive analysis. Based on the study, SMA Negeri 18 Garut's education professionals have three skills to improve service quality in line with the National Education Government Regulation No. Efforts to improve school administration at SMA Negeri 18 Garut include training educational personnel, finger prints at every entry and exit, monthly motivation and morale meetings, and comparison studies with other schools. Provide care for the teaching personnel of SMA Negeri 18 Garut.
\end{abstract}

Keywords: Competence, Education Personnel, School Administration.

\section{A. INTRODUCTION}

Aktivitas manajemen berkembang dengan sangat cepat, memaksa organisasi untuk memikirkan kembali ruang lingkup organisasi mereka. Pergeseran tersebut dimaksudkan untuk meningkatkan daya saing perusahaan, namun demikian agar bisnis benar-benar kompetitif, diperlukan perencanaan dan pengelolaan (Riniwati, 2016). Manajemen sumber daya manusia adalah salah satu kegiatan manajemen yang dilakukan oleh bisnis; sebagian besar pekerjaan dilakukan oleh manusia, bahkan ketika alat lain digunakan (Mulyana, 2010). Sumber daya manusia adalah salah satu komponen terpenting dari strategi dan struktur inti setiap organisasi. Membandingkan nilai sumber daya manusia dengan faktor lain, mereka adalah aset yang paling berharga (Safrizal, 2011). Kemampuan suatu perusahaan untuk mencapai tujuan dan sasarannya sangat bergantung pada efektifitas pengelolaan sumber daya manusianya. Akibatnya, sumber daya manusia sangat penting dalam dunia bisnis (Lako \& Sumaryati, 2002). 
Upaya peningkatan mutu pendidikan bukanlah persoalan yang mudah, mereka membutuhkan pendekatan multi yang melibatkan berbagai pemangku kepentingan (Cahyono \& Iswati, 2018). Dalam konteks ini, kualitas pendidikan tidak terbatas pada pendidikan berbasis kurikulum, tetapi mencakup semua faktor yang berkontribusi secara langsung atau tidak langsung terhadap pengembangan tenaga kependidikan yang berkualitas (Fitrah, 2017). Lembaga pendidikan dapat meningkatkan kinerja pendidik dengan menerapkan sistem manajemen yang efektif yang berfokus pada kualitas pendidik, memungkinkan mereka untuk menciptakan pendidik yang berkualitas di bidang pendidikan (Gaol \& Siburian, 2018).

Untuk mengembangkan Sumber Daya Manusia (SDM) yang unggul dan terampil, Sekolah merupakan lembaga pendidikan yang vital. Hal ini hanya dapat dicapai dengan menerapkan sistem manajemen sekolah yang efektif dan efisien (Amirudin, 2017). Ada sepuluh elemen penentu pelaksanaan proses pendidikan yang hebat, menurut Townsend dan Butterworth dalam Makawimbang (2011) partisipasi dan rasa tanggung jawab instruktur serta pengembangan staf terjadwal adalah dua yang paling penting.

Perlu diketahui bahwa tenaga kependidikan sekolah berperan sebagai pusat pelayanan pendidikan dalam suatu lembaga dan sebagai badan administrasi sekolah yang berhubungan langsung dengan yang diberikan di dalam dan di luar lembaga, serta mempunyai tugas dan fungsi mengemban keluar kerja operatif di sekolah diperlukan untuk mencapai tujuan organisasi (Novita, 2017). Tenaga pendidik di sekolah sangat dibutuhkan untuk membantu meningkatkan mutu pendidikan secara menyeluruh. Pasal 39 ayat 1 Undang-Undang Nomor 20 Tahun 2003 mengatur bahwa pendidikan sekolah merupakan ujung tombak pelayanan pendidikan bagi suatu lembaga. Ada juga kebutuhan akan keahlian khusus dari kepala sekolah/administrasi madrasah, direktur pelaksana, dan petugas layanan khusus. Seorang administrator sekolah/madrasah harus memiliki keterampilan pribadi, sosial, teknis, dan manajemen. Demikian pula, Pelaksana Urusan harus memiliki kecakapan personal, sosial, dan teknis, dan Pelaksana Urusan harus memiliki kompetensi di bidang urusan petugas (kompetensi pribadi, sosial, dan teknis petugas layanan khusus) (Valentina dkk, 2018).

Di SMA Negeri 18 Garut kompetensi yang dimiliki oleh tenaga kependidikan masih belum optimal seperti yang diungkapkan Kepala Tenaga Kependidikan SMA Negeri 18 Garut bahwa terdapat beberapa pelayanan yang masih belum maksimal yang dilakukan oleh tenaga kependidikan SMA Negeri 18 Garut seperti pelaporan-pelaporan yang berbentuk online, sedangkan semua kegiatan atau pelaporan yang dilakukan oleh sekolah sebagian besar dilakukan secara online.

Dilihat dari jenjang pendidikan tenaga kependidikan di SMA Negeri 18 Garut dapat dilihat pada tabel di bawah ini:

Tabel 1 Data Tenaga Kependidikan SMA Negeri 18 Garut

\begin{tabular}{|c|l|c|c|}
\hline No & \multicolumn{1}{|c|}{ Tingkat Pendidikan } & TAS Tetap & TAS Tidak Tetap \\
\hline 1 & SD & 0 & 1 \\
\hline 2 & SMP & 0 & 2 \\
\hline 3 & SMA & 0 & 7 \\
\hline 4 & Diploma (D3) & 1 & 3 \\
\hline 5 & Sarjana (S1) & 2 & 7 \\
\hline 6 & Pasca Sarjana (S2) & 0 & 0 \\
\hline
\end{tabular}


ARTIKEL

\begin{tabular}{|c|c|c|}
\hline Jumlah & $\mathbf{3}$ & $\mathbf{2 0}$ \\
\hline Total & \multicolumn{2}{|c|}{$\mathbf{2 3}$} \\
\hline
\end{tabular}

Sumber: Profil SMA Negeri 18 Garut (2020)

Dari tabel diatas dapat dilihat bahwa kompetensi yang dimiliki tenaga kependidikan SMA Negeri 18 Garut seharusnya sudah cukup baik, dilihat dari jenjang pendidikan yang dimiliki tenaga kependidikan SMA Negeri 18 Garut dimana jumlah lulusan S1, D3 dan SMA sudah terbilang cukup dalam melaksanakan pelayanan yang baik di SMA Negeri 18 Garut.

Tabel 2 Data Pelatihan/BIMTEK Tenaga Kependidikan SMA Negeri 18 Garut

\begin{tabular}{|c|l|c|c|}
\hline \multirow{2}{*}{ No } & \multicolumn{1}{|c|}{ Kompetensi } & \multicolumn{2}{c|}{ Pelatihan/BIMTEK } \\
\cline { 3 - 4 } & & Sudah & Belum \\
\hline 1 & Pelaksana Urusan Kepegawaian & $\checkmark$ & - \\
\hline 2 & Pelaksana Urusan Administrasi Keuangan & $\checkmark$ & - \\
\hline 3 & Pelaksana Urusan Administrasi Sarana dan Prasarana & $\checkmark$ & - \\
\hline 4 & Pelaksana Urusan Hubungan Sekolah dengan Masyarakat & - & $\checkmark$ \\
\hline 5 & Pelaksana Urusan Administrasi Persuratan dan Arsip & - & $\checkmark$ \\
\hline 6 & Pelaksana Urusan Administrasi Kesiswaan & - & $\checkmark$ \\
\hline 7 & Pelaksana Urusan Administrasi Kurikulum & $\checkmark$ & - \\
\hline
\end{tabular}

Sumber: SMA Negeri 18 Garut

Dari table diatas dapat dilihat bahwa kompetensi yang dimiliki oleh tenaga kependidikan yang dimiliki oleh SMA Negeri 18 Garut dilihat dari factor pelatihan / BIMTEK di SMA Negeri 18 Garut terlihat masih belum maksimal, karena masih ada beberapa pelaksana urusan yang masih belum pernah mengikuti kepelatihan atau BIMTEK di bidangnya, bahkan menurut Kepala Tenaga Kependidikan SMA Negeri 18 Garut bahwa disetiap bidang tidak semuanya mengikuti pelatihan hanya beberapa saja bahkan ada beberappa pegawai baru yang masuk di beberapa bidang.

Selain mengelola sistem secara rinci dan rapi, tenaga kependidikan adalah tenaga administrasi yang harus memiliki keterampilan dan profesionalisme di bidang administrasi sekolah agar penyelenggaraan pendidikan berjalan lancar sesuai dengan struktur yang disesuaikan dengan keunggulan individu, selain mengelola sistem secara detail dan rapi. Sedangkan yang menjadi ketertarikan penulis mengangkat judul tersebut adalah keingin tahuan penulis mengenai kompetensi tenaga kependidikan di SMA Negeri 18 Garut dalam meningkatkan mutu pelayanan sekolah, karena kompetensi tenaga kependidikan di sekolahan tersebut yang penulis ketahui dari kepala tenaga kependidikan dan komite sekolah belum sepenuhnya maksimal, baik dalam pelayanan terhadap siswa, orang tua siswa atau pelaporan online yang terkadang masih belum optimal.

\section{B. TINJAUAN PUSTAKA}

\section{Administrasi}

Admistrasi merupakan gabungan asal kata "ad" dan "ministrate". Kata "ad" berarti dama dengan "to" dalam bahasa Inggris, yang bermakna "ke" atau "kepada". Dan "ministrate" sama artinya dengan kata "to serve" atau "to conduct" yang berarti "melayani", "membantu", atau "mengarahkan" (Sutikno \& Arha, 2018) 
Administrasi digambarkan sebagai dua orang atau lebih yang bekerjasama untuk mencapai tujuan yang telah ditentukan dengan menggunakan alasan tertentu (Siagian, 2004). Administrator mengontrol, mendorong, dan menawarkan fasilitas bisnis bagi individu untuk mencapai tujuan yang ditentukan, menurut Tead, sebagaimana dikutip oleh Westra (2009) dalam Administrasi Negara: Tindakan individu (eksekutif) dalam suatu organisasi. Suatu administrasi, sebagaimana dijelaskan oleh Hadari Nawawi dalam (Inu Kencana 2003), melibatkan pengelolaan operasi organisasi dalam mencapai tujuan bersama.

\section{Kompetensi}

Kompetensi berasal dari istilah competence, yang mengandung pengertian kebutuhan, kapasitas, dan wewenang dalam bahasa Latin. Ketika datang ke kompetensi, itu dapat didefinisikan dalam hal kemampuan, pengetahuan, dan perilaku individu. Kemampuan dan kualitas seorang pegawai didefinisikan dalam Peraturan Pemerintah No. 101 Tahun 2000 Pasal 3 sebagai pengetahuan, sikap dan perilaku yang diperlukan untuk tugas dan jabatannya.

Pasal 1 (10) UU Ketenagakerjaan No. 13 Tahun 2003 mendefinisikan kompetensi sebagai pengetahuan, keterampilan, dan sikap kerja yang memenuhi standar yang dipersyaratkan. Sebagaimana diatur dalam Peraturan Pemerintah (PP) No. 23 Tahun 2004, sertifikasi kompetensi kerja mengacu pada pembuktian kompetensi secara sistematis dan objektif melalui uji kompetensi sesuai dengan kriteria kompetensi kerja Indonesia dan internasional. Menurut Robert A. Roe (2001), kompetensi dapat didefinisikan sebagai kapasitas seseorang untuk melaksanakan suatu posisi atau tugas serta kemampuan seseorang untuk menggabungkan keterampilan dan pengetahuan dengan keyakinan pribadi.

\section{Tenaga kependidikan}

Untuk tenaga administrasi di sekolah/madrasah, ada aturan yang ditetapkan pada tahun 2008 oleh Menteri Pendidikan Nasional. Selain itu, pengelola sekolah/madrasah harus memiliki keterampilan personal, sosial, teknis, dan manajemen, serta petugas layanan khusus harus memiliki keterampilan pribadi, sosial, dan teknis untuk melaksanakan urusan (kompetensi personal, sosial, dan teknis petugas layanan khusus).

Ada dua istilah dalam administrasi: pemerintahan dan usaha. "Tata" mengacu pada aturan atau peraturan yang harus dipatuhi oleh semua orang, proses dimana seseorang mengarahkan usahanya menuju tujuan tertentu. Dengan kata lain, itu adalah sesuatu yang Anda lakukan, atau sesuatu yang Anda coba lakukan. "Organisasi dan Administrasi Teknologi dan Pendidikan Kejuruan” oleh Suharsimi Arikunto (1990) menawarkan wawasan tentang hal berikut: Dalam administrasi, mulai dari menerima (mengumpulkan), merekam, memproses, menyimpan, dan merencanakan, hingga menggandakan dan mengirim semua informasi dibutuhkan oleh pimpinan organisasi untuk mengambil keputusan yang dipertimbangkan.

\section{METODE}

Penulis penelitian ini menggunakan metodologi penelitian kualitatif dalam hubungannya dengan analisis deskriptif. Menurut falsafah postpositivisme, penelitian kualitatif adalah metode penelitian yang digunakan untuk mengkaji kondisi objek alam (sebagai lawan dari eksperimen) dimana peneliti sebagai instrumen kunci, teknik pengumpulan 
data dilakukan dengan triangulasi (gabungan), analisis data bersifat induktif/kualitatif, dan hasil penelitian kualitatif lebih menekankan makna pada materi pelajaran (Sugiyono, 2017).

\section{HASIL DAN PEMBAHASAN}

\section{Kompetensi Tenaga Kependidikan di SMA Negeri 18 Garut}

Tenaga kependidikan merupakan bagian terpenting disuatu sekolah terutama dalam bidang pelayanan administrasi, Tenaga kependidikan adalah tenaga administrasi sekolah yang bertugas memberikan dukungan layanan administrasi untuk seluruh warga sekolah dalam hal teknis administratif, oleh karena itu setiap tenaga kependidikan dari setiap bagian baik pelaksana urusan ataupun pelaksana layanan khusus harus mempunyai kompetensi yang baik dalam memberikan pelayanan agar menghasilkan pelayanan yang bermutu sehingga tujuan sekolah bisa tercapai dengan baik.

Selain itu, tenaga kependidikan harus menunjukkan kompetensi untuk meningkatkan kinerja mereka di tempat kerja, di samping melengkapi persyaratan sertifikasi. Kepala bagian tata usaha dan tenaga tata usaha harus memiliki kualifikasi dan sertifikat pendidikan, dengan setiap jenjang pendidikan mensyaratkan pendidikan minimal SLTP, kecuali petugas atau petugas pelayanan khusus seperti tukang kebun, penjaga sekolah, petugas kebersihan, sopir, dan kurir. Sedangkan standar kompetensi khusus tenaga administrasi sekolah meliputi kompetensi sosial, kompetensi teknis, dan kompetensi kepribadian.

a. Kompetensi Kepribadian

Adalah penting bahwa setiap anggota staf kependidikan memiliki seperangkat ciri kepribadian tertentu: integritas dan akhlak mulia; kontrol diri; kepercayaan diri pada kemampuan seseorang; fleksibilitas; ketekunan; disiplin; daya temu; dan akuntabilitas.

Disimpulkan bahwa tenaga kependidikan memiliki kompetensi kepribadian berikut berdasarkan wawancara dengan responden yang beragam: Sebagai akibat dari etos kerja tenaga kependidikan, rata-rata tenaga kependidikan dari wilayah sekitar SMAN 18 Garut merasa lebih santai dalam bekerja; Pengendalian diri tenaga kependidikan dalam melaksanakan tanggung jawabnya mengakibatkan konflik antar warga sekolah berkurang karena semua masalah dibahas dengan cara yang tepat; Akibatnya, ada kesalahan dalam pekerjaan yang masih perlu diperbaiki. Hal ini disebabkan masih adanya tenaga kependidikan tertentu yang datang terlambat atau meninggalkan sekolah pada jam kerja tanpa izin, yang tentunya harus dibenahi.

Berdasarkan hasil wawancara, tenaga kependidikan di SMA Negeri 18 Garut memiliki kompetensi kepribadian yang baik, sebagaimana tertuang dalam Peraturan Menteri Pendidikan Nasional Republik Indonesia Nomor 24 Tahun 2008 tentang Standar Tenaga Tata Usaha Sekolah/Madrasah tentang Kompetensi Kepribadian.

b. Kompetensi Sosial

Ada beberapa kompetensi sosial yang harus ditunjukkan untuk mencapai kesuksesan di tempat kerja. Personil di bidang pendidikan harus memiliki kompetensi sosial untuk dapat melaksanakan program tersebut. Menurut sebuah penelitian yang diterbitkan dalam Journal of American Medical Association, kompetensi sosial seseorang memiliki dampak yang signifikan terhadap kemampuan mereka untuk belajar cara yang fleksibel dan mudah beradaptasi dengan masyarakat setempat, seperti melalui kegiatan olahraga, kelompok keagamaan, pemuda dan lain-lain. Pendidik harus memiliki pendekatan yang fleksibel untuk bersosialisasi sehingga mereka dapat bergaul secara luas dan bebas tanpa merasa terhina atau rendah diri. 
Kesimpulannya, tenaga kependidikan SMA Negeri 18 Garut memiliki keterampilan sosial yang kuat, berdasarkan temuan wawancara. Sesuai dengan Peraturan Menteri Pendidikan Nasional Nomor 24 Tahun 2008 tentang Standar Tenaga Administrasi Sekolah/Madrasah, tenaga kependidikan harus memiliki keterampilan sosial seperti kemampuan bekerja dalam kelompok dan kemampuan berkomunikasi secara efektif. Interaksi dengan siswa, rekan kerja di bidang pendidikan (seperti guru dan kepala sekolah), dan masyarakat sekitar menunjukkan kompetensi sosial dalam lingkungan pendidikan. Pengembangan kompetensi sosial dapat dilakukan dengan membangun kerjasama, mengutamakan pelayanan yang baik dan meningkatkan kesadaran berorganisasi.

c. Kompetensi Teknis

Untuk menentukan apakah tenaga kependidikan di SMA Negeri 18 Garut memberikan pelayanan yang memadai, kepribadian dan keterampilan sosial juga merupakan faktor penting. Eksekutif bisnis dan lainnya harus memiliki keahlian teknis dalam administrasi personalia, keuangan, infrastruktur, interaksi sekolah-masyarakat dan hubungan sekolah-masyarakat (TIK). Dalam uraian tugasnya, tenaga kependidikan SMA Negeri 18 Garut sangat menyadari kewajibannya di dalam kelas. Dengan mengetahui apa tugas mereka, tenaga kependidikan dapat lebih mudah memilih bagaimana melaksanakan tugas mereka sesuai dengan tanggung jawab mereka, serta siapa yang pada akhirnya bertanggung jawab untuk mereka. Oleh karena itu, setiap orang dalam pendidikan harus menyadari kewajiban dan tugasnya sehingga dapat memberikan dampak yang baik bagi keberhasilan sekolah mereka.

Menurut kemahiran teknis tenaga kependidikan SMA Negeri 18 Garut sudah sesuai dengan Peraturan Menteri Pendidikan Nasional Republik Indonesia Nomor 24 Tahun 2008 tentang Standar Tata Kelola Sekolah dan Madrasah. Kepegawaian diterbitkan pada tahun 2008. Tenaga kependidikan di SMA Negeri 18 Garut memiliki keterampilan yang sejalan dengan peraturan yang diterbitkan oleh Menteri Pendidikan Nasional tahun 2008, tentang Standar Tenaga Administrasi Sekolah dan Mudrasah (Permendiknas No. 24 Tahun 2008).

\section{Upaya Tenaga Kependidikan Untuk Meningkatkan Kualitas Administrasi Sekolah di SMA Negeri 8 Garut.}

Tenaga kependidikan SMA Negeri 18 Garut terus berupaya untuk memastikan bahwa setiap individu atau tim di setiap bagian, bahkan seluruh tenaga kependidikan di SMA Negeri 18 Garut, memiliki kompetensi yang baik. Upaya pengembangan kualitas tenaga administrasi sekolah di SMA Negeri 18 Garut, berdasarkan penelitian yang telah dilakukan oleh peneliti, khususnya oleh sebagian tenaga kependidikan SMA Negeri 18 Garut.

Tenaga kependidikan di SMA Negeri 18 Garut melakukan upaya peningkatan kualitas administrasi sekolah dengan melibatkan mereka dalam kegiatan, pengambilan sidik jari setiap keluar masuk kerja, memotivasi dan mengembangkan kinerja tenaga kependidikan secara bulanan, melakukan studi banding dengan sekolah lain, dan memperhatikan kesejahteraan tenaga kependidikan di SMA N 18. Memberikan kewenangan penuh kepada tenaga kependidikan yang ingin melanjutkan pendidikan ke jenjang yang lebih tinggi, seperti perguruan tinggi atau universitas.

Dari hasil wawancara diatas dapat disimpulkan bahwa upaya yang dilakukan oleh tenaga kependidikan SMA Negeri 18 Garut adalah dengan mengikutsertakan tenaga kependidikan dalam kegiatan pelatihan, bimtek, mengadakan fingger print pada setiap masuk 
dan pulang bekerja demi melihatkan kedisiplinan dalam bekerja, memotivasi dan mengevaluasi kinerja tenaga kependidikan pada setiap bulannya, melakukan study banding ke sekolah lain dan memperhatikan kesejahteraan tenaga kependidikan SMA Negeri 18 Garut Kemudian Memberikan izin sepenuhnya bagi Tenaga Kependidikan yang ingin melanjutkan pendidikan nya ke jenjang yang lebih tinggi seperi Kuliah.

Ada berbagai variabel yang berkontribusi dan menghambat proses administrasi di SMA Negeri 18 Garut dalam hal penyediaan layanan berkualitas tinggi dan peningkatan administrasi sekolah. Berdasarkan temuan wawancara yang diuraikan di atas, dapat disimpulkan bahwa ada unsur pendukung dan pendukung dalam proses peningkatan kualitas administrasi sekolah, untuk faktor pendukung diantaranya : kerjasama tim, kesadaran antar individu, peralatan yang memadai dan jaringan internet yang baik, sedangkan faktor penghambatnya yaitu : peralatan yang kurang memadai, orang tua yang meminta pelayanan pada hari libur, kurangnya personil dan masih ada tenaga kependidikan yang belum faham sepenuhnya dalam pengoprasian komputer.

\section{E. KESIMPULAN}

Ketrampilan dan kemampuan tenaga kependidikan SMA Negeri 18 Garut sudah sesuai dengan standar kompetensi yang diatur dalam Peraturan Nomor 24 Tahun 2008, yang mengatur bahwa tenaga kependidikan, terutama yang bekerja di bidang khusus dan pelayanan, harus memiliki tiga kompetensi: kompetensi kompetensi, kompetensi sosial, kompetensi, dan komunikasi. Tenaga kependidikan SMA Negeri 18 Garut akan mendapatkan manfaat dari unsur-unsur berikut dalam upaya mereka meningkatkan kualitas administrasi sekolah: kerjasama tim, kesadaran antar individu, peralatan yang memadai dan jaringan internet yang baik. Sementara faktor penghambat diantaranya yaitu: jaringan internet yang sering gangguan, peralatan yang kurang memadai, orang tua yang meminta pelayanan pada hari libur, kurangnya personil dan masih ada tenaga kependidikan yang belum faham sepenuhnya dalam pengoprasian komputer.

\section{DAFTAR PUSTAKA}

Amirudin, A. (2017). Kinerja Pegawai Tata Usaha dengan Mutu Layanan Administrasi di Madrasah. Al-Idarah: Jurnal Kependidikan Islam, 7(1), 126-145.

Arikunto, S. (1990). Organisasi dan Administrasi: Pendidikan Teknologi dan Kejuruan. Rajawali.

Cahyono, H., \& Iswati, I. (2018). Memahami Peran dan Fungsi Perkembangan Peserta Didik Sebagai Upaya Implementasi Nilai Pendidikan Karakter dalam Kurikulum. Elementary: Jurnal Ilmiah Pendidikan Dasar, 4(1), 47-62.

Fitrah, M. (2017). Peran Kepala Sekolah Dalam Meningkatkan Mutu Pendidikan. Jurnal Penjaminan Mutu, 3(1), 31-42.

Gaol, N. T. L., \& Siburian, P. (2018). Peran Kepala Sekolah Dalam Meningkatkan Kinerja Guru. Kelola: Jurnal Manajemen Pendidikan, 5(1), 66-73.

Inu Kencana, S. (2003). Ilmu Administrasi Publik. Jakarta: Rineka Cipta.

Lako, A., \& Sumaryati, A. (2002). Optimalisasi Kinerja Korporasi Melalui Audit Kinerja Manajemen Sumber Daya Manusia. Manajemen Usahawan Indonesia, (10). 
Makawimbang, J. H. (2011). Supervisi dan Peningkatan Mutu Pendidikan. Bandung: Alfabeta.

Mulyana, M. (2010). Manajemen Sumber Daya Manusia (Sdm) Ritel Dalam Meningkatkan Kinerja Perusahaan. Jurnal Ilmiah Ranggagading, 10(2), 164-170.

Novita, M. (2017). Sarana dan Prasarana Yang Baik Menjadi Bagian Ujung Tombak Keberhasilan Lembaga Pendidikan Islam. Nur El-Islam, 4(2), 97-129.

Riniwati, H. (2016). Manajemen Sumberdaya Manusia: Aktivitas Utama dan Pengembangan SDM. Universitas Brawijaya Press.

Roe, R. A. (2001). Competence Human Resource. Yogyakarta: Gajah Mada University Press.

Safrizal, H. B. A. (2011). Penilaian Aset Sumber Daya Manusia. Media Trend, 6(1), 11-22.

Siagian, P. S. (2004). Filsafat Administrasi. Jakarta: Haji Mas Agung.

Sugiyono. (2017). Metode Penelitian Kuantitatif, Kualitatif, dan R\&D. Bandung: Alfabeta.

Sutikno, B., \& Arha, N. (2018). Analisis Kualitas Pelayanan Administrasi Pada Kantor Camat Selangit Kabupaten Musi Rawas. Mimbar: Jurnal Penelitian Sosial Dan Politik, 7(1), 49-58.

Valentina, R., Maisyaroh, M., \& Kusumaningrum, D. E. (2018). Hubungan Kompetensi dan Motivasi Kerja dengan Kinerja Tenaga Administrasi Sekolah. JAMP: Jurnal Administrasi dan Manajemen Pendidikan, 1(1), 79-86.

Westra, P. (2009). Administrasi Perusahaan Negara: Perkembangan \& Permasalahan. Ghalia Indonesia. 